\title{
INFLUENCE OF WELDING TIME ON QUALITY OF THE FRICTION WELDED JOINT OF TWO DISSIMILAR STEELS
}

\begin{abstract}
There are several factors that influence the friction welding (FW) process, i.e. the quality of the welded joint, like the welding time, the contact pressure, the compacting pressure, the friction speed etc. The joining process is additionally complicated if the two different materials are to be welded to each other. The subject of research, presented in this paper, is the welding time of the FW process, since the level of axial and radial plastic deformation of the welded pieces and shortening of the welded part depend mainly on the welding time. The paper first presents some theoretical basics of the FW process and then, in the experimental part, the influence of the process duration is investigated. The two materials that the experimental samples were made of are the high-speed steel and the steel for tempering.
\end{abstract}

Keywords: friction welding, joint quality, welding time, friction time, compacting time

\section{Introduction}

Here is considered welding of high-speed steel and tempering steel, the two materials that significantly differ with respect to their mechanical, technological and other characteristics, both in the solid state and in the hot state. To execute a welded joint of these two, completely different steels is a very complex task. The friction welding process was selected for joining of these two materials because it enables obtaining of the high quality joint, since the technological-metallurgical problems in friction welding of carbon and alloyed steels are significantly smaller than in their welding by some other procedures. For welding of some metals, like the two steels in question, the friction welding is frequently the only joining process that would enable obtaining a joint without presence of the brittle phases.

These two steels have different thermal conductivity and strength. This is why the welding parameters have to be selected in such a way that a sufficient degree of plastic deformation is achieved in the high-speed steel, which has the lower thermal conductivity and the higher strength in the hot state. Determination of the friction

\footnotetext{
${ }^{1}$ Assistant Professor, PhD., Faculty of Engineering, University of Kragujevac, Serbia

${ }^{2}$ Professor, PhD., Faculty of Engineering, University of Kragujevac, Serbia

${ }^{3}$ Research Associate, Mgr. Ing., Faculty of Engineering, University of Kragujevac, Serbia

${ }^{4}$ Professor, Mgr., MS., PhD., Research Center, University of Žilina, Slovakia and Faculty of

Engineering, University of Kragujevac, Serbia

${ }^{5}$ Docent, Research Center, University of Žilina, Slovakia
} 
time, as well as the total welding time, is especially important since in that way the better weldability can be realized. Though the melting temperatures of the tempering and the high-speed steel are not very different, they have different capacity for plastic deformation. That affects the configuration of the joint's surface in the joining zone (RATKOVIĆ N. 2009, ĆIRIĆ R. 2001). Eventual geometrical irregularities in the joining zone can be eliminated by increase of the welding time, as well as the compacting pressure, what influences the heat affected zone.

The friction welding of the high-speed and carbon steels is the most frequently used in manufacturing of the cutting tools.

Analyses of the friction welding of dissimilar steels were presented in papers (SAHIN M. 2005, RATKOVIĆ N. et al. 2009a, ĆIRIĆ R. 1986). The description and the detailed analysis of the friction welding of those steels are given in (RATKOVIĆ N., NIKOLIĆ R., SAMARDŽIĆ I. 2014), while the valuable results and information are present in (RATKOVIĆ, N. et al. 2009b, DENIN, G. 1989, SEREGIN A. 1986, RATKOVIĆ N. 2015, RATKOVIĆ N. et al. 2015, RATKOVIĆ N. Et al. 2017).

\section{Some theoretical basics of the friction welding process}

In the friction welding the way of introducing the heat to the joining spot is, in the physical sense, completely different from other welding processes. The base metal is heated by the heat that is transformed from mechanical energy due to friction of the two materials confronting each other in the contact zone. This is the internal heat source (by location) and the heat generation is strictly localized at the joining spot and it happens only in the thin surface layers of metals. This is one of the reasons why the friction welding has advantages with respect to some other ways of metals joining.

The mechanisms of joining metals in the solid state, as well the process itself, are very complex. The substance of joining is forming the metal bonds between the components of the base metals, which are created when the pure metal surfaces approach each other to a distance that is of the order of magnitude of the crystal lattice parameters.

Considering that the metal surfaces of real solids are not ideally smooth and clean at the beginning of welding, the contact is realized only at peaks of roughness of those surfaces. Increase of the contact area is realized through the plastic deformation of the micro volumes of the metal layers close to the contact surfaces, at temperatures lower than the melting temperature of the base metals. That is why the external pressure is applied. Conditions for beginning of the plastic deformation are facilitated by the decrease of the yield stress, since for majority of metals it is decreasing with a temperature increase. 
The friction welding process occurs successively in several phases. The time sequences, characterizing the process, include a series of the accompanying phenomena and changes within the contact zone, as well. Those phases are relatively very short, from several fractions of a second up to several seconds. The physical contact first occurs almost over the whole friction surface when the phase of the initial friction begins and lasts until the friction moment reaches its first maximum. The interaction between the metal particles occurs at the contact points, so the strong adhesive bonds are created, leading to shear of the material particles and transfer of one metal onto the other. It is proven that at smaller friction speeds those particles are mainly being transferred in the zones closer to the perimeter of the bar, while at higher speed this occurs closer to the bar's axis. After that, the phase of unstable friction starts during which the temperature increases and material endures a large plastic deformation. The thickness of the high plasticity zone could reach up to $2 \mathrm{~mm}$. At that point the mixing of the two metals' particles occurs.

In the following phase the stable friction occurs, when the plastic deformation increases, especially in the layers close to the surface. The dynamic thermal balance is established between the developed heat and the heat transferred by conduction into the base metals, over the total heat affected zone and into the environment via the extruded metal, as well.

In the joining zone, the highly plasticized metal is moving according to mechanism of the swirling (turbulent) flow, as well as the rotational flow. In this phase, the initial diffusion processes are intensified.

Then follows the stadium of the final friction and the braking occurs. The character, form and magnitude of the plastic deformation are changing due to the abrupt decrease of the friction speed. Deformation is moving towards the periphery of the bar and large quantity of material is being extruded out of the joint zone, what causes the shortening of components. At the end, the compacting of the parts is introduced, without the action of the friction moment. There is no rotation of the welded parts. The intensive moving of material occurs in both the axial and radial directions. Between the two base metals the metal bonds are activated and the common crystal lattices are formed in the boundary layers. That is to say, the solid welded joint is formed.

\section{The welding time}

The quality of the friction welded joint is mainly determined by the three basic control variables, which influence the metallurgical, physical and mechanical properties of the frictionally welded joint. Those variables are the friction speed, 
pressure and welding time. The total welding time is the sum of the friction and the compacting time.

The friction time depends on properties of the base metals (like the strength at the forging temperature, thermal conductivity, and phase transformations), welding speed, friction pressure, shape and dimensions of the welded components, etc. When dissimilar materials are welded, the friction time is selected with respect to the material of the lower hardness. The following expression is recommended for the friction time determination (RATKOVIĆ N. et al. 2009b):

$$
t_{f}=\left(r^{2} \cdot R_{m f} \cdot n\right) /\left(\lambda \cdot p_{f} \cdot \rho\right)
$$

where: $r, \mathrm{~mm}$ is the radius of the welded parts; $R_{m f}, \mathrm{MPa}$ is the tensile strength at the forging temperature; $\lambda, \mathrm{MPa}$ is the thermal conductivity; $\rho, \mathrm{kg} / \mathrm{dm}^{3}$ is the material density; $p_{f}, \mathrm{MPa}$ is the friction pressure; $n$ is the number of rpms.

The friction time $\left(t_{f}\right)$ is the time needed for the contact surfaces to heat up to the required temperature $T_{\max }$ to provide for the secure welding process. The way of the friction time selection cannot be generally defined due to the high deformation speed in the joint zone and due to the complex conditions at the friction surface.

The compacting time $\left(t_{c}\right)$ is the time of the compacting pressure action. Duration of the compacting time must be sufficient to secure the complete realization of the plastic deformation, as well as the recrystallization process, but it must not be too long since the long compacting time can increase the danger of the cold cracks appearance. According to experimental data, extension of the compacting time increases the tensile strength of the joint.

The friction time can last from 1 to $50 \mathrm{~s}$, while the compacting time is 2 to $3 \mathrm{~s}$. In this case the friction time was varying within the range from 3 to $18 \mathrm{~s}$.

\section{Tests results and discussion}

The experimental part of this work consisted of the friction welding of cylindrical samples of the tempering and the high-speed steel. The initial dimensions of the samples and the joining scheme are presented in Figure 1. 

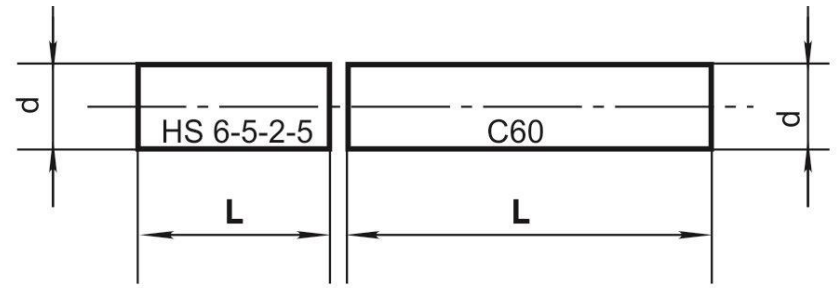

$\mathrm{L}^{\text {HS 6-5-2-5 }}=44.5 \mathrm{~mm}$

$\mathrm{L}^{\mathrm{c} 60}=80.6 \mathrm{~mm}$

$\mathrm{d}^{\mathrm{HS} 6-5-2-5}=16.5 \mathrm{~mm}$

$\mathrm{d}^{\mathrm{C} 60}=16 \mathrm{~mm}$

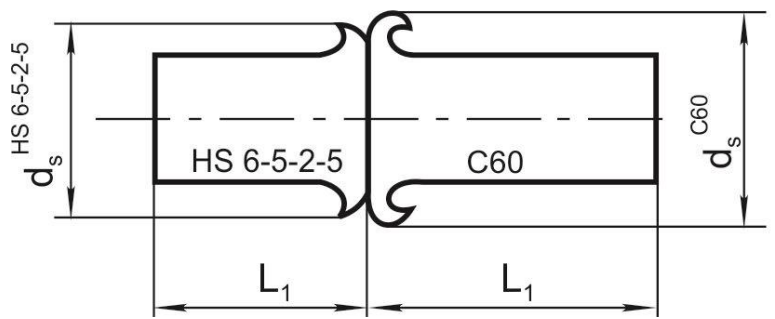

Fig. 1. Schematic drawing of the high-speed and tempering steels' samples before (top figure) and after the joining (bottom figure).

Source: own study

\subsection{The base metals}

High-speed steel (HS 6-5-2-5) is the special type molybdenum-tungsten-cobalt high-speed. It is used for highly strained tools, for high cutting speeds, for machining of the stainless and thermo-resistant steels. It is convenient for casting, as well. Chemical composition of this steel is given in Table 1 .

Carbon tempering steel (C60) is a steel that has the high wear resistance and hardenability. It is applied in general metal working industry. Chemical composition of this steel is given in Table 1.

Table 1. Chemical composition of the HS 6-5-2-5 and C-60 steels, \%

\begin{tabular}{|c|c|c|c|c|c|c|c|c|c|c|}
\hline & $\mathbf{C}$ & $\mathbf{S i}$ & $\mathbf{M n}$ & $\mathbf{C r}$ & $\mathbf{M o}$ & $\mathbf{V}$ & $\mathbf{W}$ & $\mathbf{C o}$ & $\mathbf{P}$ & $\mathbf{S}$ \\
\hline HS6-5-2-5 & 0.82 & 0.45 & 0.40 & 4 & 5 & 1.9 & 6.5 & 5.5 & 0.035 & 0.035 \\
\hline C-60 & 0.63 & 0.194 & 0.82 & - & - & - & - & - & 0.045 & 0.045 \\
\hline
\end{tabular}

Source: own study 


\subsection{Changes of geometrical parameters}

The experimental investigation was aimed at establishing the influence of the friction and the compacting time on variation of sizes of samples in the longitudinal and lateral directions, with values of the friction and compacting pressures kept constant. The welding regime parameters were: the friction pressure during the friction time was $p_{f}=80 \mathrm{MPa}$, the compacting pressure during the compacting time was $p_{c}=200 \mathrm{MPa}$. Number of rpms was $n=2400 \mathrm{rpm}$.

Changes of the following dimensions were monitored: diameter of samples at joint $D_{j}$, diameter increment $\Delta d_{j}$, samples' length $L_{l}$, total length $L_{t}$, samples' shortening $\Delta L$ and total shortening $\Delta L_{t}$. Measurements results of the dimensions' changes during the welding are presented in Table 2. The graphic presentation of the dimensions' increase is shown in Figure 2.

Results of measurements show that diameters of samples are increasing with increase of the friction time, while the samples are simultaneously shortening.

In Figure 3 is shown the change of samples' dimensions from the initial values to their final values in terms of the friction time.

In Figure 4 is presented the macroscopical appearance of the samples' joints longitudinal sections.

Experimental results have shown that the radial and tangential displacements are increasing with approaching to the contact surface. For the same cross-section, those displacements are increasing with increase both of the friction pressure and the friction time.

For instance, in the measurements plane, which lies at a distance of $0.5 \mathrm{~mm}$ from the contact surface, the displacements are significantly larger than in the plane that is at a distance of $1 \mathrm{~mm}$ from the joint. That points to appearance of the high plastic deformation.

What concerns the friction time influence on displacements, it was shown that in the initial phases of the heating process displacements are increasing with time. However, after entering the final phase of the stable friction, the displacements remain practically unchanged. 
Table 2. Influence of the friction time on changes of the monitored dimensions for the C60 and $\mathrm{HS}$ 6-5-2-5 joint

\begin{tabular}{|c|c|c|c|c|c|c|c|c|c|c|c|c|}
\hline Time & $\mathbf{S}$ & 3 & 4.5 & 6 & 7.5 & 9 & 10.5 & 12 & 13.5 & 15 & 16.5 & 18 \\
\hline \multirow{2}{*}{$\mathbf{D}_{\mathbf{j}}$} & C60 & 18 & 18.2 & 19.2 & 21.5 & 22.7 & 23.3 & 26.4 & 26.4 & 26.6 & 28 & 28.5 \\
\hline & HSS & 16.8 & 17 & 17.7 & 20 & 20.6 & 22 & 22.2 & 22.5 & 23 & 23.4 & 24 \\
\hline \multirow{2}{*}{$\Delta \mathbf{d}_{\mathbf{j}}$} & $\mathbf{C 6 0}$ & 2 & 2.2 & 3.2 & 5.5 & 6.7 & 7.3 & 10.4 & 10.4 & \begin{tabular}{|l|}
10.6 \\
\end{tabular} & 12 & 12.5 \\
\hline & HSS & 0.3 & 0.5 & 1.2 & 3.5 & 4.1 & 5.5 & 5.7 & 6 & 6.5 & 6.9 & 7.4 \\
\hline \multirow{2}{*}{$\mathbf{L}_{1}$} & C60 & 80.5 & 80.1 & 80 & 79.3 & 79 & 77.9 & 76.2 & 77.4 & 76.1 & 75.6 & 75.3 \\
\hline & HSS & 44.4 & 44.3 & 44 & 43 & 42.9 & 42.7 & 42.6 & 42.4 & 41.8 & 41.7 & 41.6 \\
\hline $\mathbf{L}_{\mathbf{t}}$ & C60 & 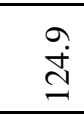 & $\underset{\stackrel{J}{J}}{\stackrel{+}{*}}$ & $\stackrel{\searrow}{\beth}$ & ก̃ & $\stackrel{9}{\beth}$ & $\begin{array}{l}0 \\
\stackrel{0}{0}\end{array}$ & $\begin{array}{l}\infty \\
\infty \\
\equiv\end{array}$ & $\begin{array}{l}\infty \\
\stackrel{0}{=}\end{array}$ & 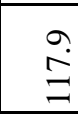 & $\stackrel{\text { J }}{\text { I }}$ & $\begin{array}{l}\hat{\sigma} \\
=\end{array}$ \\
\hline \multirow{2}{*}{$\Delta \mathbf{L}$} & HSS & 0.1 & 0.5 & 0.4 & 1.3 & 1.6 & 2.7 & 4.4 & 3.2 & 4.5 & 5 & 5.3 \\
\hline & C60 & 0.1 & 0.2 & 0.5 & 1.5 & 1.6 & 1.8 & 1.9 & 2.1 & \begin{tabular}{|l|}
2.7 \\
\end{tabular} & 2.8 & 2.9 \\
\hline$\Delta \mathbf{l}_{t}$ & - & 0.2 & 0.7 & 0.9 & 2.8 & 3.2 & 4.5 & \begin{tabular}{|l}
6.3 \\
\end{tabular} & 5.3 & 7.2 & 7.8 & 8.2 \\
\hline
\end{tabular}

Dimensions are given in $\mathrm{mm}$

Source: own study

\subsection{The plastic deformation parameters}

The following plastic deformation parameters were calculated: relative sliding of samples with respect to each other, strain and the strain rate. The relative sliding was calculated according to the following expression:

$$
\gamma=\frac{\sqrt{(\Delta r)^{2}+(\Delta s)^{2}}}{\Delta \ell},
$$

where $\Delta r$ and $\Delta s$ are the corresponding displacements in the radial and tangential directions, respectively and $\Delta \ell$ is shortening;

The strain was calculated according to the following expression:

$$
\varepsilon=\left(\gamma+\sqrt{1+\gamma^{2}}\right)^{\frac{1}{1-k}}-1
$$

where $k$ is the corresponding strain coefficient;

The strain rate was calculated according to the following expression:

$$
\dot{\varepsilon}=\frac{\Delta \varepsilon}{t},
$$

where $t$ is the compacting time. 
Zeszyty Naukowe

No 1(6) 2017

Quality. Production. Improvement

s. $1-11$
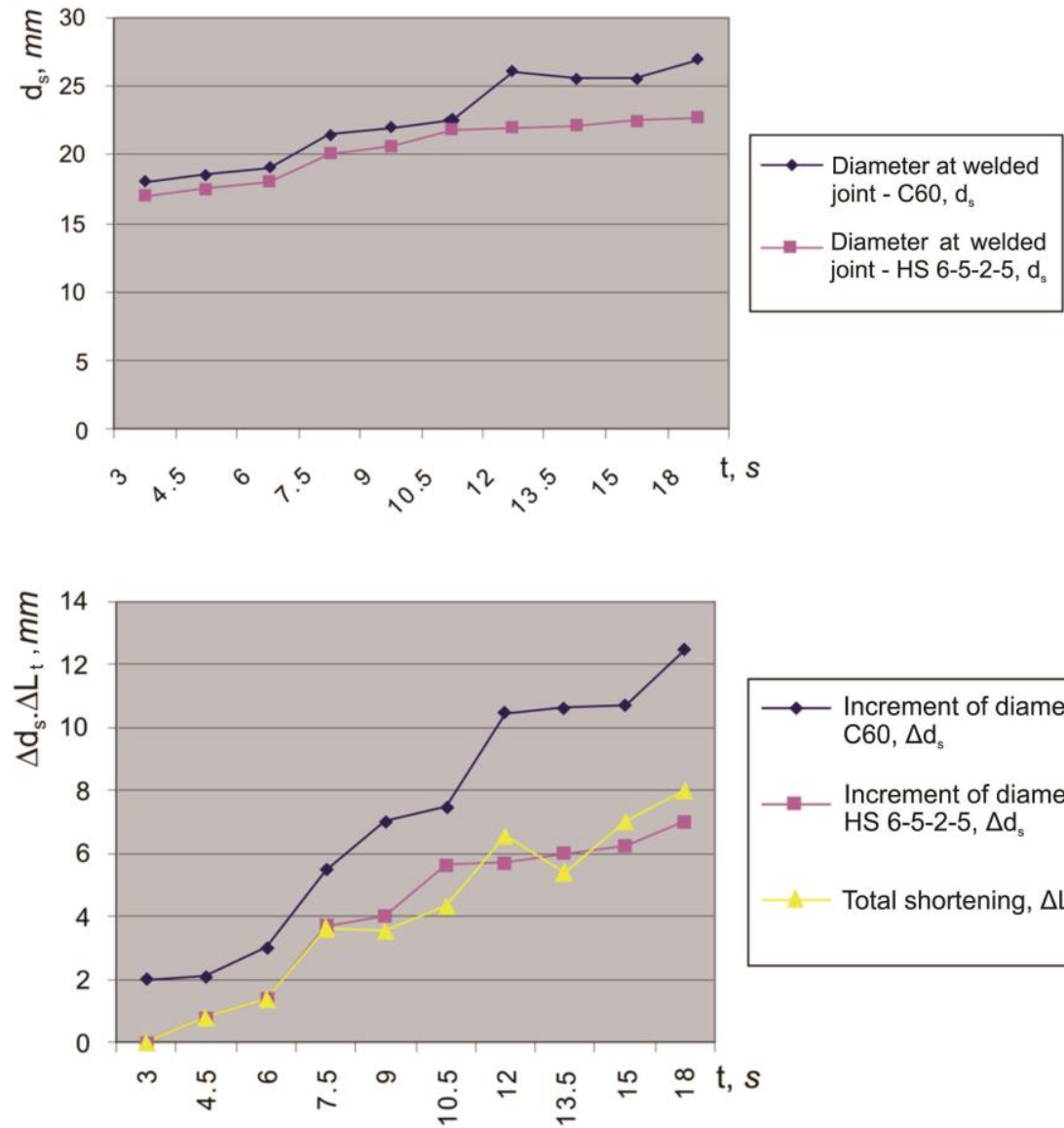

Fig. 2. Influence of the friction time on change of the samples diameter and length. Source: own study

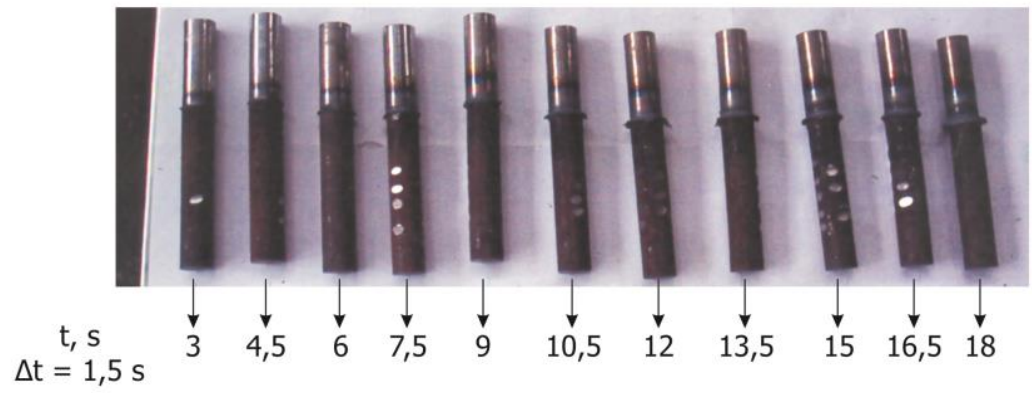

Fig. 3. Macroscopical appearance of welded samples for different values of the friction time.

Source: own study 
Values of the calculation results of the deformation parameters are given in Table 3 , for the distance of $0.5 \mathrm{~mm}$ from the joining line, for the points at the radii of 2.5 $\mathrm{mm}$ and $4 \mathrm{~mm}$, on the high-speed steel sample.

a)
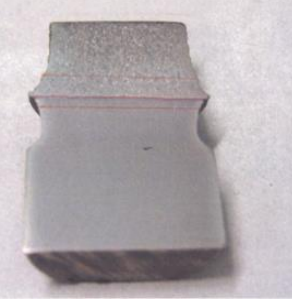
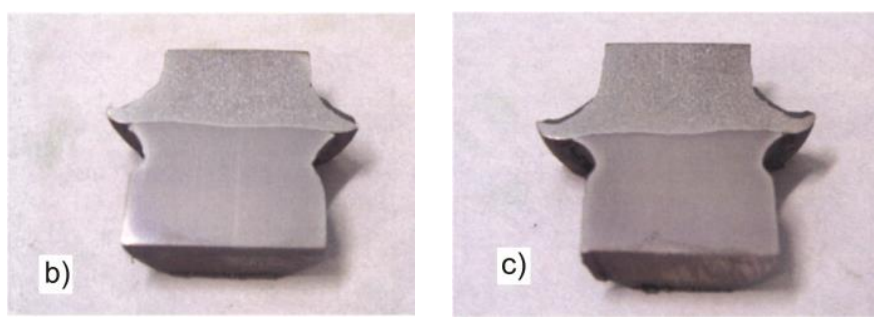

Fig. 4. Samples of steels HS 6-5-2-5 and C60 cross-sections for different values of the friction time, a) $6 \mathrm{~s}, \mathrm{~b}) 12 \mathrm{~s}$, c) $18 \mathrm{~s}$.

Source: own study

Table 3. Dependence of the plastic deformation parameters on the friction time for the highspeed steel HS 6-5-2-5

\begin{tabular}{|c|c|c|c|c|c|c|c|}
\hline & & \multicolumn{6}{|c|}{$\begin{array}{l}\text { Position of the measurement point with respect to the } \\
\text { rotation axis }\end{array}$} \\
\hline \multirow{6}{*}{$p_{f}=80 \mathrm{MPa}$} & \multirow{3}{*}{$t, \mathbf{s}$} & \multicolumn{2}{|c|}{$r=2.5 \mathrm{~mm}$} & \multicolumn{4}{|c|}{$r=4 \mathrm{~mm}$} \\
\hline & & \multicolumn{6}{|c|}{ Parameters of plastic deformation } \\
\hline & & $\gamma$ & $\varepsilon$ & $\dot{\varepsilon}$ & $\gamma$ & $\varepsilon$ & $\dot{\varepsilon}$ \\
\hline & 6 & 0.38 & 0.2 & 0.12 & 1.54 & 0.84 & 0.32 \\
\hline & 10 & 1.48 & 0.81 & 0.24 & 2.54 & 1.29 & 0.39 \\
\hline & 13 & 1.76 & 0.94 & 0.32 & 3.1 & 1.52 & 0.52 \\
\hline
\end{tabular}

Source: own study

\section{Summary}

The objective of this research was to establish what influence imposes the welding time on quality of the friction welded joint of the two dissimilar steels. Among several important influential parameters, the welding time is selected for investigation, since it affects the appearance of the welded joint, its strength and reliability, i.e. the level of axial and radial plastic deformation of the welded pieces and shortening of the welded part. 
The friction welding was applied for joining two dissimilar steels, the high-speed steel HS 6-5-2-5 and the tempering steel C-60. Those materials have different mechanical and metallurgical properties, the most important for the friction welding process being the strengths and thermal conductivity coefficients.

The presented analysis of experimental results confirms the assumption that the process variables significantly influence appearance, course and final result of the plastic deformation of both welded steels. The level and rate of the plastic deformation are increasing with increase of the friction time and especially with approaching to the joint plane, as well as with moving away from the rotation axis. This is due to nature of the friction process, where the deformation intensifies the displacements of the micro-volumes of material towards the perimeter.

Results show that the deformation is larger for the tempering steel than for the high-speed steel, what should be expected taking into account the difference in the two steels strengths and deformability (primarily ductility). At the constant stress conditions (unchanged friction pressure and compacting pressure), the plastic deformation increases with increase of the friction time, what confirms the theoretical assumptions, as well.

The general conclusion is that the friction welding can be successfully applied for joining these two types of steels and the quality of the executed welded joint depends solely on the process parameters, i.e. on their optimal values.

Taking into account the dynamics and complexity of the plastic deformation process, it is hard to relate all the relevant parameters into a single mathematical model. However it is extremely valuable to determine the duration of all the influential parameters. The friction time serves as an example, which represents the duration (and rate) of all the deformation phenomena from the beginning until the final forming of the friction welded joint.

\section{Acknowledgement}

This research was partially financially supported by European regional development fund and Slovak state budget by the project "Research Centre of the University of Žilina" - ITMS 26220220183 and by the Ministry of Education, Science and Technological Development of Republic of Serbia through grants: ON174004, TR35024. The authors are very grateful for this funding. 


\section{Bibliography}

1. ĆIRIĆ R. 1986 Contribution to analysis of properties of the friction welded joints of $\check{C} 7680$ with $\check{C} 1730$. Master Thesis, Faculty of Mechanical Engineering, Belgrade, Serbia.

2. ĆIRIĆ R. 2001 Structural changes in the vicinity of the welded joint of steels. "Welding and Welded Structures". 1-2, pp. 31-36.

3. DENIN G. 1989 Optimization of setting values for friction welding with continuous drive. Specialized information from KUKA. Augsburg, (In German).

4. RATKOVIĆ N. 2009 Modeling of the machine parts of various forms of the welding process, Doctoral dissertation, Faculty of Mechanical Engineering, Kragujevac, Serbia.

5. Ratković N., Sedmak A., Jovanović M., Lazić V., Nikolić R., Krstić B. 2009a Physical and metallurgical changes during the friction welding of the high-speed steel and the tempering steel. "Tehnički vjesnik-Technical Gazette". 16, pp. 27-31.

6. Ratković N., Sedmak A., Jovanović M., Lazić V., Nikolić R., Krstić B. 2009b Quality analysis of Al-Cu joint realized by friction welding. "Tehnički vjesnik-Technical Gazette". 16(3), pp. 3-7

7. RATKOviĆ N., NikOliĆ R., SAMARDŽIĆ I. 2014 Structural, chemical and deformation changes in friction welded joint of dissimilar steels. "Metallurgy". 53(4), pp. 513-516.

8. RATKOvić N., ARsić D., LAZiĆ V., Nikolić R., SEDMAK A. 2015 Influence of friction welding parameters on hardness, microstructure and mechanical properties of the Al-Cu joint. Proc. $7^{\text {th }}$ International Scientific and Expert Conference TEAM 2015. Belgrade, 1516 October 2015, pp. 359-363.

9. Ratković N., Arsić D., Lazić V., Nikolić R., Hadzima B., Palček P., Sedmak A. 2017 Influence of friction welding parameters on properties of the Al-Cu joint, "FME Transactions", 45(1), pp. 165-171.

10. SAHIN M. 2005 Joining with Friction Welding of high-speed and medium-carbon steel. "The International Journal of Advanced Manufacturing Technology". 49, pp. 527-534.

11. SEREGIN A. 1986 Degree of plastic deformation in friction welding of metals. "SP" 8. (In Russian). 